\title{
Cycles and sinks: two key elements of a circular economy
}

\author{
Ulrich Kral ${ }^{1}$ - Leo S. Morf ${ }^{2} \cdot$ Dana Vyzinkarova ${ }^{1,3} \cdot$ Paul H. Brunner $^{1}$
}

Received: 9 February 2018 / Accepted: 7 August 2018 / Published online: 30 August 2018

(c) The Author(s) 2018

\begin{abstract}
Modern products contain a wide range of substances. Some of them are hazardous, cause risks for human and environmental health, and impair the quality of future secondary resources produced by recycling. Ways must be explored to extract detrimental substances during recycling and direct them to safe final sinks. Final sinks can be end-of-pipe technologies (man-made sinks) or environmental media (natural sinks). The latter are limited in capacity and need to be protected against overloading. The paper presents a rationale for sinks in a circular economy, and supports decision-making regarding recycling materials with detrimental constituents. It is based on two case studies of regional flows of polycyclic aromatic hydrocarbons in spent asphalt pavements, and copper in waste flows. Applying a scenario approach, effective measures are discussed for circulating safe and high-quality materials while observing sink limitations. The results demonstrate the link between mass flows, quality of recycled material, and the need for final sinks. The optimization challenge of keeping cycles clean by costly measures for safe disposal of hazardous materials in sinks is discussed. Man-made sinks such as waste to energy plants and sanitary landfills are key for designing a circular economy that meets environmental and resource-oriented goals.
\end{abstract}

Keywords Waste management $\cdot$ Canton of Zurich $\cdot$ Urban mining $\cdot$ Copper $\cdot$ PAHs

\section{Introduction}

The material turnover of modern economies is so high that future supply of raw materials is at risk in a long-term perspective. Thus, recycling has been introduced to improve resource availability. Many countries, such as Japan and the European Union, included circular economy in their national policies and promote recycling $[1,2]$. Today, recycling processes are fed with materials that contain not only useful and valuable but also hazardous substances. Numerous substance

Electronic supplementary material The online version of this article (https://doi.org/10.1007/s10163-018-0786-6) contains supplementary material, which is available to authorized users.

Ulrich Kral

ulrich.kral@tuwien.ac.at

1 Institute for Water Quality and Resource Management, Technische Universität Wien, Vienna, Austria

2 Office of Waste, Water, Energy and Air, Canton of Zurich, Switzerland

3 Mozambique Recycling Association (AMOR), Beira, Mozambique are potentially shifted to the recycling material and pose risk for product quality and human and environmental health.

Even Pivnenko and Astrup [3] found "very little analysis that describes the fate of chemicals throughout the lifecycle of materials ending up in recycled products", the phenomena about contamination of recycling material has been addressed in several studies. For instance, carcinogenic substances contaminate the asphalt cycle $[4,5]$, brominated flame retardants and phalates contaminate the plastic cycle [6-8], mineral oils, bisphenol A, diethylhexyl phthalate contaminate the paper cycle $[9,10]$, heavy metals contaminate recyclable grit [11], or copper in scrap contaminates the steel cycle [12]. These case studies show that additional endeavours are needed to ensure the qualitative concern of keeping material cycles clean. To measure the quality of material cycles, various scientific methodologies with a material system perspective have been developed. For instance, Knapp, Allesch, Muller et al. [13] presented a methodology to estimate the transfer of contaminants into recycling products, Rechberger and Brunner [14] proposed an entropy-based approach to consider quality aspects in material flows, and Rigamonti, Niero, Haupt et al. [15] recommend to consider quality aspects of waste-derived materials in life-cycle 


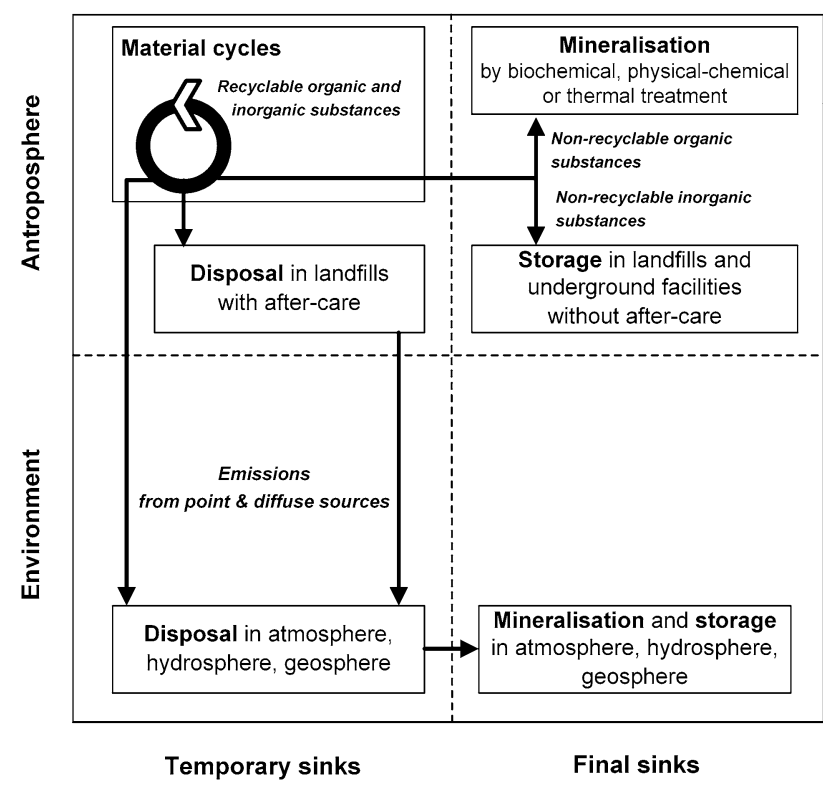

Fig. 1 Concept of clean cycles and final sinks

analysis. The intention of this article is neither to apply one of these evaluation methods nor to add a new method. It is to respect the phenomena of contaminated material cycles and to demonstrate the consequences of keeping material cycles clean.

When it comes to more holistic strategies for avoiding contaminated material cycles, Sakai [16] suggested a "Clean, Cycle and Control" concept, and Brunner [17] added the need for final sinks to get rid of non-recyclable materials to keep the material cycles clean. It is inherent to the strategies that detrimental materials have to be removed from the cycles, and that they must be either transformed into harmless substances, or disposed of in safe storages for very long period of times (Fig. 1). These transformation and storage processes are so-called "final sinks". Final sinks can be located in both the anthroposphere and the environment, and are substance-specific. Organic substances are subject of mineralization in transformation processes such as perfluorooctanesulfonate in waste to energy (WTE) plants. Inorganic substances are, for instance, subject of safe storage in landfills depending on the composition of the disposed waste, and on technical as well as geological barriers.

The goal of this paper is to present a rationale for the need for sinks in a circular economy. Case studies for polycyclic aromatic hydrocarbons (PAHs) in the asphalt cycle and copper $(\mathrm{Cu})$ in waste flows are presented to demonstrate the linkage between clean cycles and final sinks, and to support decision-making for waste and resource management. Achieving the goal includes three major steps. First, the tool "material flow analysis" (MFA) is presented. Second, the tool is used to analyse regional $\mathrm{PAH}$ and $\mathrm{Cu}$-containing waste flows. The status-quo refers to the year 2013, and the scenarios follow a clean cycle and final sink strategy. Third, based on the MFA results, conclusions regarding the management of PAH and $\mathrm{Cu}$ and regarding the relevance of clean cycles and final sinks in a circular economy are outlined.

\section{Methodology}

The approach is based on the tool "material flow analyses" as defined by Brunner and Rechberger [18] and includes four steps:

1. Selection of substances (see Sect. "Selection of substances").

2. System definition in space and time (see Sect. "System definition in space and time").

3. Identification of relevant flows, stocks and processes (see Sect. "Identification of relevant flows, stocks and processes").

4. Determination of mass flows and stocks (see Sect. "Determination of mass flows and stocks").

\section{Case studies}

This section provides an overview for applying the tool "material flows analysis" in the two case studies. The full documentation can be found in the report "Schutz und Nutzung von Senken durch die Zürcher Abfall- und Ressourcenwirtschaft", published by Kral, Vyzinkarova and Brunner [19]. Detailed data for the PAHs case study are given in "Controlling legacy substances in material cycles-cases of polycyclic aromatic hydrocarbons (PAH) and di-2-ethylhexyl phthalate (DEHP)" by Vyzinkarova and Brunner (manuscript in preparation).

\section{Selection of substances}

Due to the substance-specific nature of final sinks, PAHs and $\mathrm{Cu}$ have been chosen as representative for organic and inorganic substances, respectively. Both substances potentially lower the quality of recycling products and pose risks for human and environmental health. The background for selecting PAHs and $\mathrm{Cu}$ is the following:

- Polycyclic aromatic hydrocarbons in asphalt pavements: PAHs are included in mass products, such as tar used for road pavements, or tobacco smoke. They pose risks for human health [c.f. 20, 21]: Cancer of skin, lung, bladder, and digestive systems have been reported for workers and smokers exposed to mixtures of PAHs. While in the past, PAHs in tar for asphalt road 
pavement were banned and replaced by bitumen, they are still present in road pavements, as for instance, in Germany and Switzerland [4, 22]. When, at the end of their lifecycle, road pavements are recycled, PAHs become part of future construction materials. This practice keeps PAHs in the loop and prolongs PAH exposure risks. Thus, ways must be explored to remove PAHs from cycles, and to manage the remaining PAHs.

- Copper in residues from WTE plants: Copper, widely applied in construction works and consumer goods, is an essential heavy metal of comparatively high-economic value. It is well suited for recycling, resulting in less environmental impact than primary production. Thus, copper recovery from wastes is attractive and facilitates a circular economy. However, copper also represents an impurity for specific materials such as steel. Collection and waste treatment must be directed towards "clean" scrap to avoid copper traces in steel. Leachates from copper containing wastes in landfills pose a risk for human and environmental health. Measures to reduce $\mathrm{Cu}$ in landfills and to control its mobility are needed to lower these risks. Hence, copper waste management needs to be optimized towards maximum recycling of high-quality materials and least-environmental risks from landfilling.

\section{System definition in space and time}

The study area Canton Zurich, Switzerland, has been selected because waste authorities developed a long-term strategy on clean cycles and final sinks and incorporated respective principles in the planning and design of the regional waste management system. Further details regarding the strategy are given in the supplementary material.

The spatial system boundary is the administrative boundary of the Canton of Zurich and neighboring territories that import and export wastes from/to the Canton Zurich. About 1.5 Mio inhabitants are living in the Canton covering $1700 \mathrm{~km}^{2}$ [23]. Per capita, the gross domestic product (GDP) amounted to approximately 100,000 US Dollar, and the Canton of Zurich generates $22 \%$ of this GDP. About 10 tons of solid waste are produced per capita and year. The boundary for the analysis is limited to the waste and resource management system, which includes the collection, treatment and disposal of materials.

The year 2013 is chosen as temporal system boundary for the status-quo analysis, because of data quality and quantity reasons.

\section{Identification of relevant flows, stocks and processes}

The identification of relevant flows, stocks and processes depends on the presence of PAH and $\mathrm{Cu}$ within the waste and resource management system of the Canton Zurich.

The PAH case includes the following processes and flows. "Asphalt pavements" represent the source of excavated asphalt and the temporary sink for recycled material. The "collection \& separation, recycling" processes receives the excavated asphalt and delivers recyclable materials, residues sent to "sanitary landfill" and "thermal treatment plants".

$\mathrm{The} \mathrm{Cu}$ case includes the following processes and flows. The "WTE plants" cover six plants that receive municipal solid waste (MSW) from and outside of the Canton Zurich. Four out of the six plants are equipped with a wet-discharger system for bottom-ash; the one is equipped with the drydischarger system for the fine fraction and a wet-discharger for the course fraction, and the one with a dry-discharger system only. The "WTE plants" generate "bottom-ash I", which is sent to "bottom-ash treatment \& metal recovery" in the Canton Zurich. This process includes magnetic separation of metals at the WTE plant, bottom-ash treatment, magnetic metal separation and disposal at the landfill site as well as bottom-ash treatment and metal recovery at the plant in Hinwil. This process delivers "Recovered Copper" to a copper smelting plant and bottom-ash, which is disposed of in "landfills" inside the Canton Zurich and in "landfills and underground facilities" outside the Canton Zurich. The "WTE plants" also produce off-gas, which is for this study the difference of in- and outputs of solid material flows.

\section{Determination of mass flows and stocks}

For the status-quo quantification of material flows and stocks, data have been collected from various sources, such as internal reports and statistics from the Office of Waste, Water, Energy and Air of the Canton of Zurich, expert estimates, public statistics, reports from business associations, literature data, and material flow studies in Switzerland. The full data documentation is given in the annex of the report "Schutz und Nutzung von Senken durch die Zürcher Abfallund Ressourcenwirtschaft" [19].

The scenario analysis considers options that support the "clean cycle and final sink" concept (c.f. Table 1). In general, the PAH concentration in recyclable and disposable materials are lowered, which requires final sinks to get rid of non-recyclable and non-disposable materials. The scenario for copper diverts copper from sanitary landfills to the recycling pathway. The stakeholders developed WTE technologies further and introduced new metal recovery technologies. In detail, to expand metal extraction from bottom-ash, the wet-discharge system was 
Table 1 Measures considered for the scenario to pursue the "clean cycle and final sink" concept
PAHs
$\mathrm{Cu}$

Clean cycles Limits for PAH concentration are set at $250 \mathrm{ppm}$ for recycling materials

Increasing the recoverability of metallic $\mathrm{Cu}$ from waste flows up to $95 \%$ by selective deconstruction and separation

Decreasing the mixing of $\mathrm{Cu}$ with other scrap metals for steel making

Final sink Limits for PAH concentration are set at $250 \mathrm{ppm}$ for disposable materials. Wastes with more than $250 \mathrm{ppm}$ are directed towards thermal treatment (TT) such as WTE plants, cement kilns or other

Preventing disposal of materials containing $\mathrm{Cu}$ in sanitary landfills

Lowering $\mathrm{Cu}$ content of landfill material

Fig. 2 Status quo for goods containing PAHs (a) and for PAHs (b) flows and stocks. Numbers are rounded to one significant digit. $T T$ thermal treatment
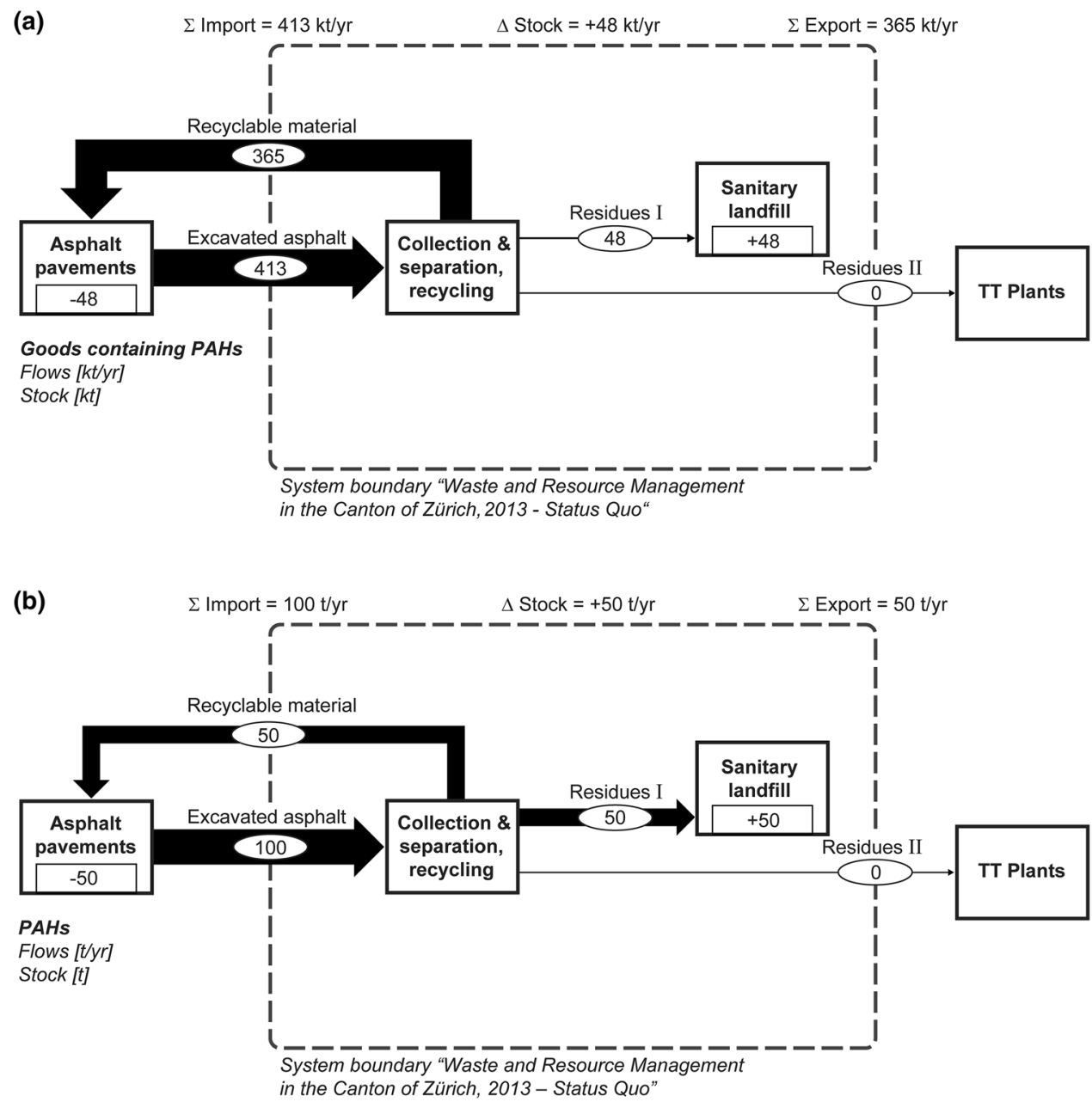

replaced by a dry-discharge system at the WTE plant in Hinwil, Switzerland [14]. In addition, a new, advanced metal extraction plant for bottom-ash with sophisticated metal separation and recovery technologies was installed. These improvements allow recovering $95 \%$ of metallic $\mathrm{Cu}$ contained in bottom-ash. Changes in import and export of bottom-ash are also considered.

\section{Results and discussion}

This section describes the material stocks and flows for both, the status quo and the scenario. 
Fig. 3 Scenario for goods containing PAHs (a) and for PAHs (b) flows and stocks. Numbers are rounded to one significant digit. TT thermal treatment
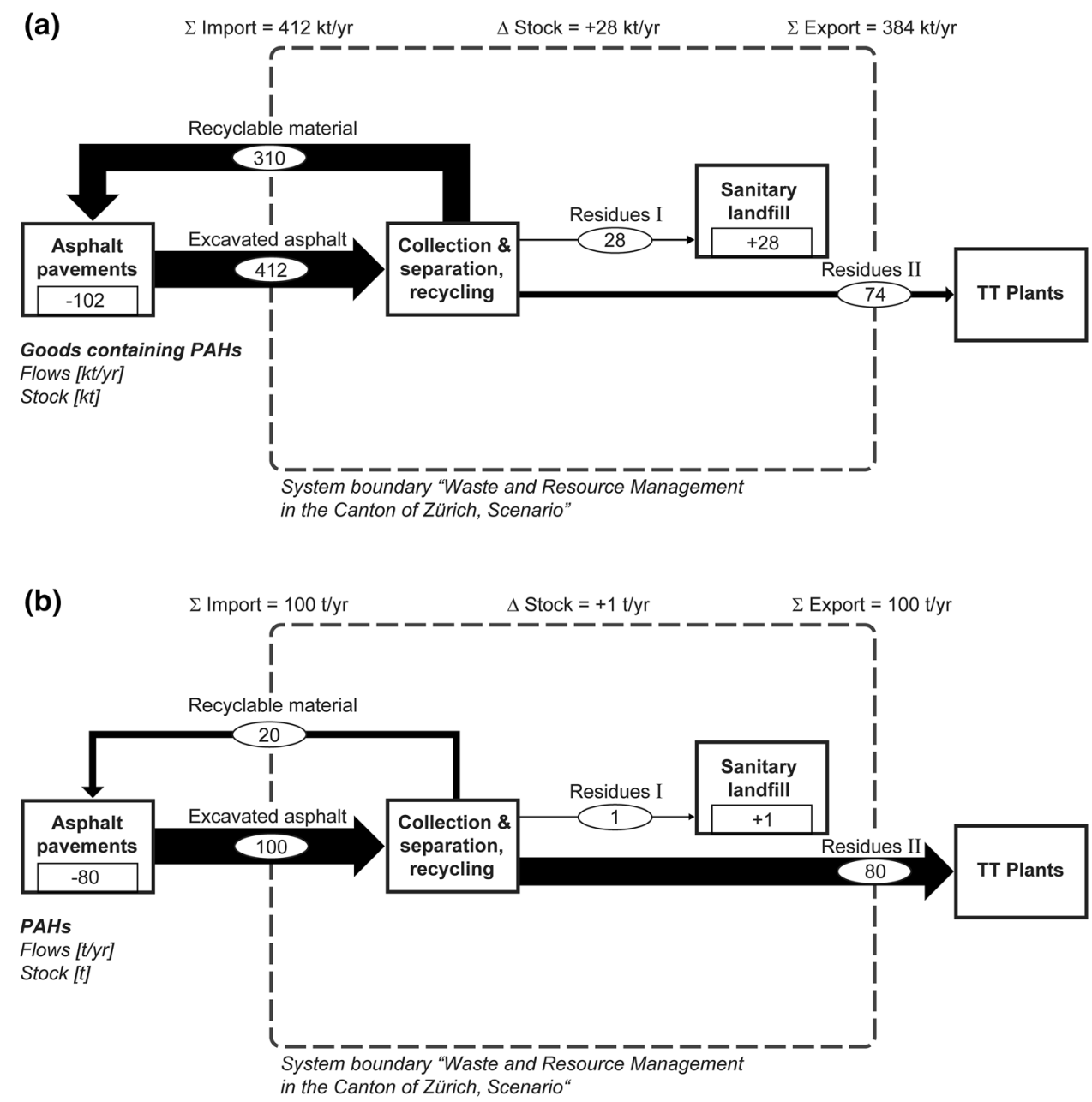

\section{Polycyclic aromatic hydrocarbons}

In the status quo of the year 2013 (Fig. 2), about 410 kilotons (kt) asphalt entered the waste and resource management system, of which $88 \%$ were recycled. The remaining $12 \%$ were disposed off in landfills. The excavated asphalt contained about 100 tons (t) PAH, of which 50\% were recycled and used again in construction material and $50 \%$ were disposed of in sanitary landfills. At this time, no asphalt was sent to thermal treatment (TT) plants.

The results of the scenario (Fig. 3) show that from the $410 \mathrm{kt}$ asphalt $75 \%$ (310 kt) are recycled, while 7\% (28 kt) are sent to sanitary landfills and $18 \%$ (74 kt) have to be treated in TT plants. Following this scenario, $80 \%$ of the PAHs will become destroyed by mineralization, $20 \%$ will remain in the cycle, and about $1 \%$ still ends up in sanitary landfills.

\section{Copper}

In the status-quo of the year 2013 (Fig. 4), about $900 \mathrm{kt} /$ year of non-recyclable MSW were collected and imported, respectively, and treated in the Canton Zurich. The flows contain approximately $1270 \mathrm{t} \mathrm{Cu}$ /year. After recovering copper from bottom-ash, about $220 \mathrm{t} \mathrm{Cu}$ /year were sent to recyclers. Approximately, $1080 \mathrm{t} \mathrm{Cu}$ /year in bottom-ash were disposed off in sanitary landfills.

The scenario measures keep the flow of non-recyclable MSW constant, but increases the recovery rate of metallic $\mathrm{Cu}$ from 53 to $95 \%$ and also recovers copper from previously exported bottom-ash flows (Fig. 5). This results 670 t/year of recovered copper sent to a smelter plant and reduces $\mathrm{Cu}$ in disposed bottom-ash from $1050 \mathrm{t} \mathrm{Cu} /$ year to $620 \mathrm{t} \mathrm{Cu} /$ year.

\section{Conclusions}

This section draws conclusions regarding the $\mathrm{PAH}$ and $\mathrm{Cu}$ management in the Canton Zurich and reflects upon clean cycles and final sinks as key elements for circular economy. 
(a)

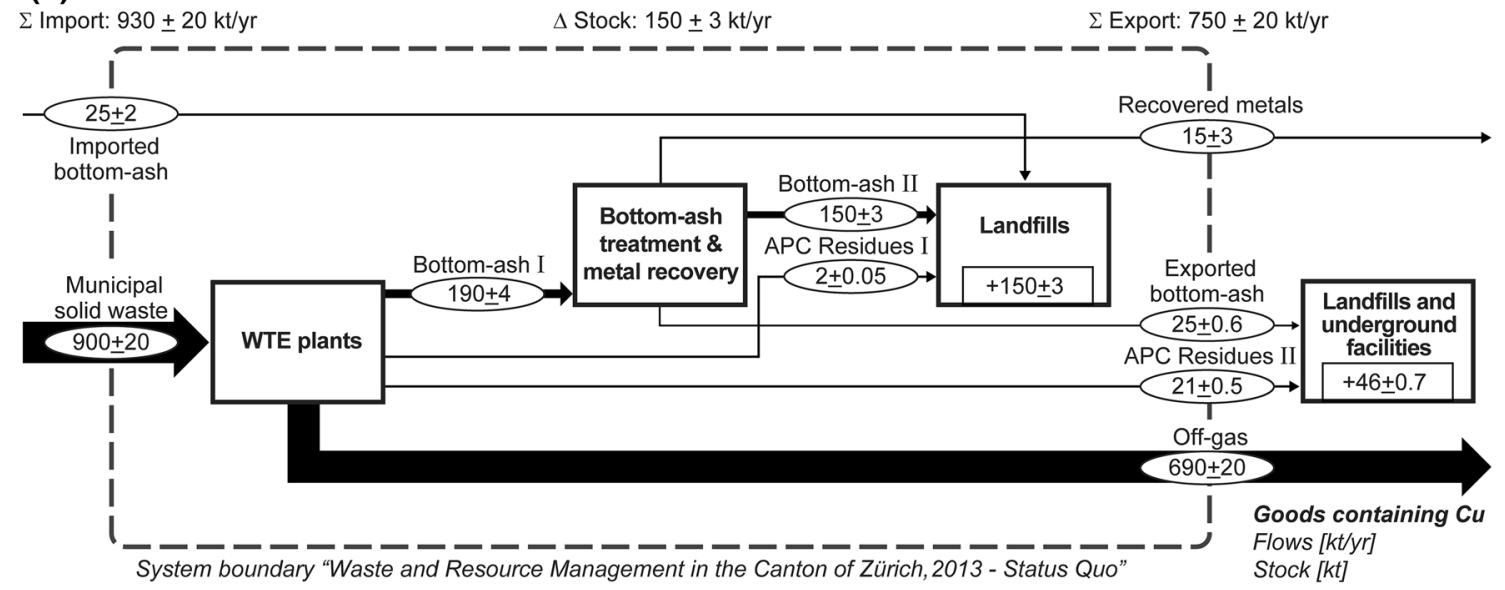

(b)

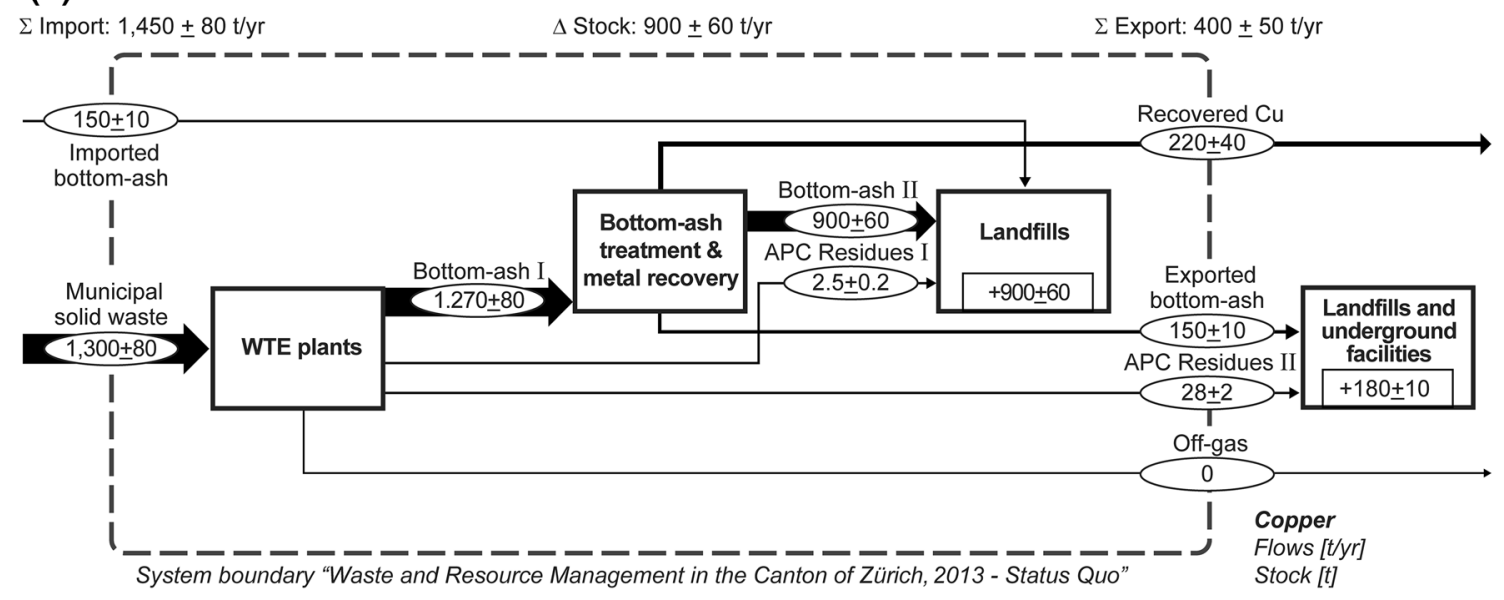

Fig. 4 Status quo for goods containing $\mathrm{Cu}(\mathbf{a})$ and for $\mathrm{Cu}$ (b) flows and stocks. Numbers are rounded to one significant digit (depending on the leading digit of the uncertainty)

\section{PAH and Cu management}

The findings from the PAH case study allow the following conclusions:

1. There is a clear link between clean material cycles and the need for final sinks (c.f. Table 2). For PAHs, the decrease of the acceptable PAHs concentration in recycling and disposal materials increases the need for WTE and other TT plants as final sinks for PAHs. Consequently, the cleaner a material cycle is supposed to be, the more capacities for triage and final sink are needed.

2. The recycling rate of asphalt pavements drops roughly from 88 to $75 \%$ because waste fractions with higher PAHs content are removed from material cycles and disposal routes to landfills. This reduces PAHs exposure risks at construction and landfill sites. As a conclusion for PAHs, decreasing the recycling rate increases higher product qualities.
3. Protecting human health and environment are drivers for selecting appropriate options for waste collection and treatment. Prioritizing thermal treatment over recycling is justified, because it eliminates PAHs and thus exposure risks.

The findings from the $\mathrm{Cu}$ case study allow the following conclusions:

1. Like for PAHs, there is a clear link between circular economy and the need for final sinks. The increase in the $\mathrm{Cu}$ recovery rate of WTE plants from 53 to $95 \%$ reduces the demand for sanitary landfills as final sink, but does not entirely remove their necessity (c.f. Table 2). This is because certain amounts of - particularly non-metallic- $\mathrm{Cu}$ quantities remain in bottom-ash because of technological and economic constraints of the recovery process. However, the $\mathrm{Cu}$ concentration in bottomash changes from about $6^{\prime} 000$ to $3^{\prime} 000 \mathrm{mg} \mathrm{Cu} / \mathrm{t}$, which 
(a)

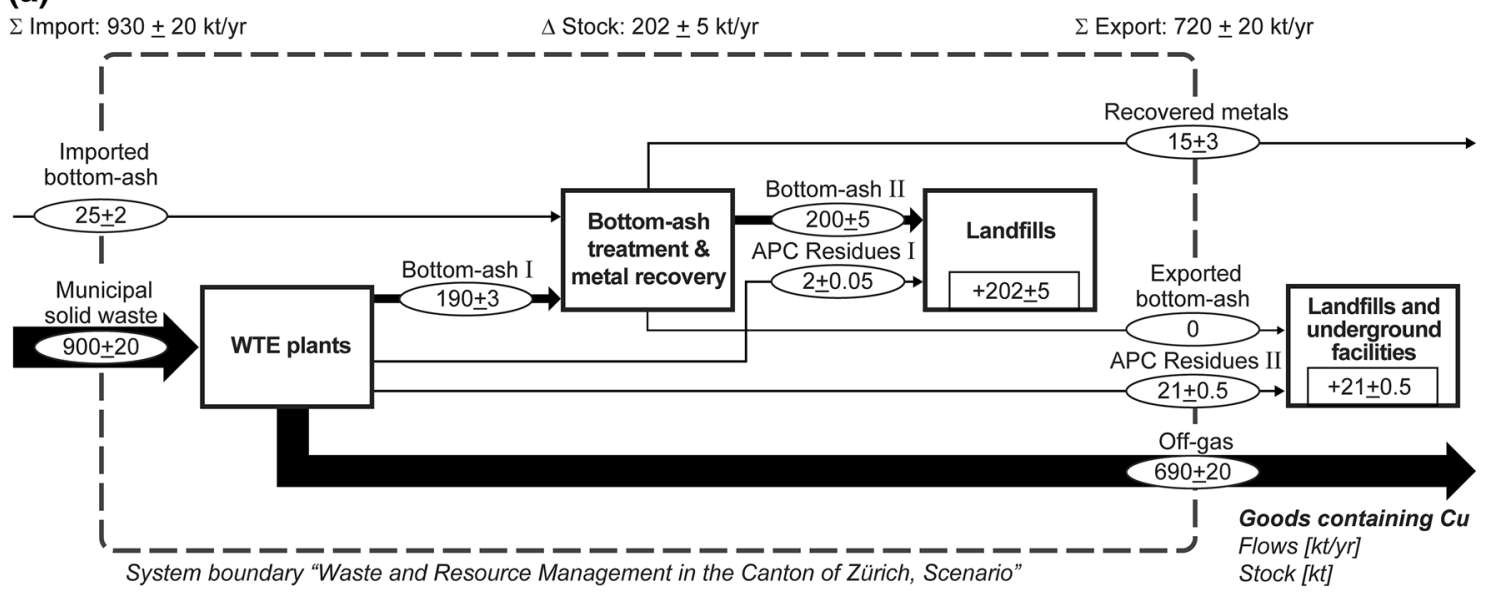

(b)

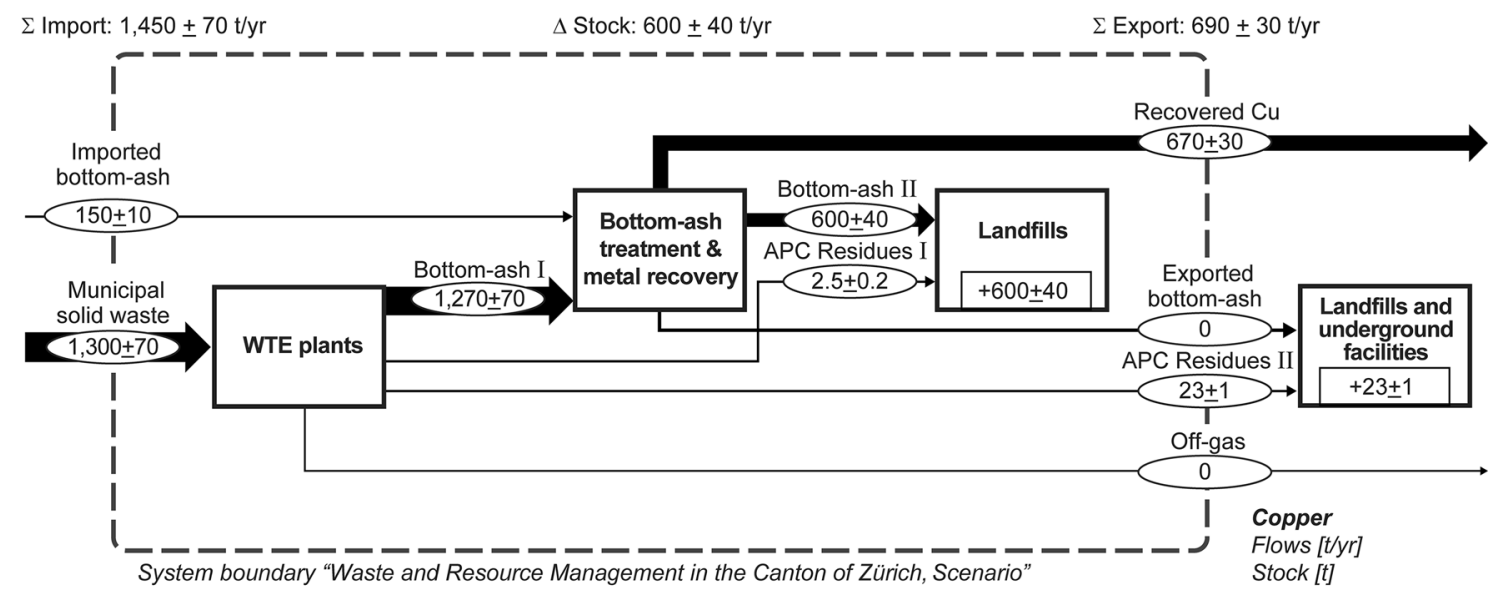

Fig. 5 Scenario for goods containing $\mathrm{Cu}$ (a) and for $\mathrm{Cu}$ (b) flows and stocks. Numbers are rounded to one significant digit (depending on the leading digit of the uncertainty)

reduces the leachate potential and exposure risks below present legal standards.

2. The grade of chemical homogeneity of the waste plays a key role for material recovery. Highly heterogeneous waste flows, such as MSW, contain in part materials that cannot yet be mechanically sorted and recovered efficiently. Since a WTE plant acts as a huge homogenizer, the combination of incineration and bottom-ash treatment allows effective recovery of $\mathrm{Cu}$ (and other metals) from heterogeneous MSW flows. In both, the status quo as in the scenario case, relatively homogeneous waste flows are collected individually (e.g. metal scrap, glass), sorted and sent to recycling facilities. In addition, the scenario case allows to recover more and additional metals from WTE residues.

3. In traditional waste management, WTE is installed to mineralize organic waste constituents, to reduce waste volume, to destroy microorganisms, and to recover energy. It is optimized to reduce environmental impacts from waste. Additional requirements emerge in the context of a circular economy that cannot be fulfilled with traditional WTE technologies. Changes to more advanced technologies, such as optimization of discharger systems for bottom-ash, improve the bottom-ash qualities in view of effective metal recovery up to $95 \%$. However, the efforts for $\mathrm{Cu}$ recovery need to be contextualized with the entire $\mathrm{Cu}$ cycle. The $\mathrm{Cu}$ quantities in bottom-ash that are directed to sanitary landfills stand for about $5 \%$ of the total annual consumption. ${ }^{1}$ From a resource point of view, the questions are (a) if this loss

\footnotetext{
${ }^{1}$ In Switzerland, about $8.1 \mathrm{~kg} \mathrm{Cu} / \mathrm{cap}$ yr enter the use phase in mobile goods, infrastructure and buildings [24]. In the scenario case, $0.4 \mathrm{~kg} \mathrm{Cu} / \mathrm{cap}$ in bottom-ash are directed to sanitary landfills, amounting to $5 \%$ of the annual consumption.
} 
Table 2 Need for sinks and recovery rates for materials and associated mass flows of PAHs and $\mathrm{Cu}$ : figures represent PAH in asphalt pavements, and $\mathrm{Cu}$ in wastes that enter WTE plants, including MSW, bulky waste from construction sites, sewage sludge, car shredder residues, residues from treating separately collected waste, and residues from treating waste electric and electronic equipment

\begin{tabular}{|c|c|c|c|c|}
\hline & \multicolumn{2}{|c|}{ PAHs [tons/year] ${ }^{\mathrm{a}}$} & \multicolumn{2}{|c|}{$\mathrm{Cu}$ [tons/year] $^{\mathrm{a}}$} \\
\hline & Status-quo & Scenario & Status-quo & Scenario \\
\hline \multicolumn{5}{|l|}{ Need for sinks } \\
\hline Temporary sinks & 50 & 20 & 220 & 670 \\
\hline Finals sinks & 50 & 80 & 1230 & 780 \\
\hline Total need for sinks & 100 & 100 & 1450 & 1450 \\
\hline \multicolumn{5}{|l|}{ Recovery rates } \\
\hline $\begin{array}{l}\text { Substance level } \\
\text { (PAHs resp. Cu) }\end{array}$ & $50 \%$ & $20 \%$ & $53 \%^{\mathrm{b}}$ & $95 \%^{\mathrm{b}}$ \\
\hline Material level & $88 \%$ & $75 \%$ & $\mathrm{nr}^{\mathrm{c}}$ & $n r^{\mathrm{c}}$ \\
\hline
\end{tabular}

${ }^{\mathrm{a}}$ The numbers are rounded to one significant digit

${ }^{\mathrm{b}}$ The recycling rate refers to the metallic copper content, which is about $50 \%$ of the total copper content in bottom-ash

${ }^{\mathrm{c}} n r$ not relevant

poses a resource problem, and if yes, (b) if other losses of $\mathrm{Cu}$ can be recovered with less expenditure and environmental impacts than the remaining $\mathrm{Cu}$ in bottom-ash.

\section{Circular economy}

This paper presents a rationale for the need for sinks in a circular economy. It is based on a case study approach and we recognize that specific case studies are needed to provide a robust knowledge base for decision-making in other regions. The case studies have several general implications for the need of sinks in a circular economy, and for effective decision-making regarding the allocation of materials to cycles and sinks.

1. In affluent societies, a total of about 10 tons of solid waste is generated per person and year. This amount includes valuable as well as hazardous substances that impede high-quality recycling and pose risks for human and environmental health. For a sustainable circular economy, a large fraction of these detrimental substances must be extracted during recycling, and must be directed to safe final sinks. Final sinks can be end-of-pipe technologies or environmental media. The latter are limited in capacity and need to be protected against overloading. Despite increased recycling efforts, non-recyclables remain and, therefore, the need for final sinks persists. The need for final sinks can be reduced by means of substance bans, product lifetime extension and recycling. However, sinks cannot be prevented completely.
2. For the sake of high-quality recycling products, a circular economy has also to provide final sinks. The installation of final sink capacities such as WTE plants, sanitary landfills or underground storages requires long-term planning. Reliable, consistent and harmonized data on the amount of wastes and their hazardous constituents as well as harmonized definitions for performance indicators are needed. This will allow for a better design of waste management and for monitoring its progress towards effective decision-making in a circular economy [e.g., 10, 25].

3. Circular economy does not mean that recycling should be à priori favoured against alternative treatment and disposal options, such as WTE and landfilling. It is the combination of measures that enable the attainment of the ultimate goal of waste management, which is environmental protection and resource conservation according to the European Waste Framework Directive and proposed amendments [26, 27]. Indeed, boosting circular economy by means of recycling rates neglects the qualitative aspect of recycling products. Quality refers to technical feasibility and properties as well as hazardousness. Concluding, the definition of recycling rates needs to be amended by qualitative criteria in view of environmental and resource oriented goals [c.f. 28].

4. Resource policies should also consider the costs for providing final sinks in the waste management sector: What is more effective to reach the goals of a circular economy-cleaning the cycles and providing final sinks, or contaminated cycles with less need for final sinks but lower product quality? To answer this question requires economic as well as environmental and resource optimization.

\section{Outlook}

The paper presents a rationale for sinks in a circular economy, and supports decision-making regarding recycling materials without detrimental constituents. The methodology is mainly based on "material flow analysis", taking into account regional material stocks and flows under defined conditions. Before implementation, this analysis needs to be complemented by an economic, ecological and social evaluation to facilitate robust decision-making for keeping material cycles clean and for planning final sink capacities. We encourage the scientific community and the waste and resource management sector to address the phenomena of contaminated material cycles and to consider it for further improvement of waste and resource management strategies. 
Acknowledgements Open access funding provided by TU Wien (TUW). We are grateful for collection and provision of abundant data by the Office of Waste, Water, Energy and Air of the Canton of Zurich (AWEL), in particular Mr. Elmar Kuhn and Mr. Franz Adam. Figures 2, 3, 4, 5 have been drawn by Ingeborg Hengl.

Open Access This article is distributed under the terms of the Creative Commons Attribution 4.0 International License (http://creativeco mmons.org/licenses/by/4.0/), which permits unrestricted use, distribution, and reproduction in any medium, provided you give appropriate credit to the original author(s) and the source, provide a link to the Creative Commons license, and indicate if changes were made.

\section{References}

1. METI (2002) Act on the promotion of effective utilization of resources (Act No. 48 of 1991). Ministry of Economy Trade and Industry (METI). http://www.meti.go.jp. Accessed 14 Feb 2018

2. Bourguignon D (2014) Turning waste into a resource - moving towards a "circular economy". Briefing for the European Parliament. European Parliamentary Research Service (EPRS). http:// www.europarl.europa.eu. Accessed 14 Feb 2018

3. Pivnenko K, Astrup TF (2016) The challenge of chemicals in material lifecycles. Waste Manag 56:1-2. https://doi. org/10.1016/j.wasman.2016.08.016

4. Rubli S (2013) Dynamische modellierung der Asphalt- sowie PAK-Lager und Flüsse in den Strassen der Region St. Gallen, Thurgau, Zürich und Fürstentum Liechtenstein (in German). Energie- und Ressourcen-Management GmbH. Schlieren

5. Deutscher Bundesrechnungshof (2014) Bemerkungen des Bundesrechnungshofes 2013 zur Haushalts- und Wirtschaftsführung des Bundes - Weitere Prüfungsergebnisse (in German). Bonn. https://www.bundesrechnungshof.de. Accessed 16 Aug 2018

6. Chen SJ, Ma YJ, Wang J, Chen D, Luo XJ, Mai BX (2009) Brominated flame retardants in children's toys: concentration, composition, and children's exposure and risk assessment. Environ Sci Technol 43(11):4200-4206. https://doi.org/10.1021/es9004834

7. Samsonek J, Puype F (2013) Occurrence of brominated flame retardants in black thermo cups and selected kitchen utensils purchased on the European market. Food Addit Contam Part A Chem Anal Control Expo Risk Assess 30(11):1976-1986. https://doi. org/10.1080/19440049.2013.829246

8. Pivnenko K, Eriksen MK, Martin-Fernandez JA, Eriksson E, Astrup TF (2016) Recycling of plastic waste: presence of phthalates in plastics from households and industry. Waste Manag 54:44-52. https://doi.org/10.1016/j.wasman.2016.05.014

9. Panel on Contaminants in the Food Chain (CONTAM) (2012) Scientific opinion on mineral oil hydrocarbons in food. EFSA J 10(6):2704. https://doi.org/10.2903/j.efsa.2012.2704

10. Pivnenko K, Laner D, Astrup TF (2016) Material cycles and chemicals: dynamic material flow analysis of contaminants in paper recycling. Environ Sci Technol 50(22):12302-12311. https ://doi.org/10.1021/acs.est.6b01791

11. Zamhöfer S, Schmidt B (2001) Recycling von strassenkehricht. Möglicheiten der nutzung als streugut nach schwermetallentfrachtung. Umweltwiss Schadst Forsch 13(3):145-152. https:// doi.org/10.1065/uwsf2001.05.054

12. Daehn KE, Cabrera Serrenho A, Allwood JM (2017) How will copper contamination constrain future global steel recycling?
Environ Sci Technol 51(11):6599-6606. https://doi.org/10.1021/ acs.est.7b00997

13. Knapp J, Allesch A, Muller W, Bockreis A (2017) Methods to estimate the transfer of contaminants into recycling products case study from Austria. Waste Manag 69:88-100. https://doi. org/10.1016/j.wasman.2017.08.035

14. Rechberger H, Brunner PH (2002) A new, entropy based method to support waste and resource management decisions. Environ Sci Technol 36(4):809-816. https://doi.org/10.1021/es010030h

15. Rigamonti L, Niero M, Haupt M, Grosso M, Judl J (2018) Recycling processes and quality of secondary materials: Food for thought for waste-management-oriented life cycle assessment studies. Waste Manag 76:261-265. https://doi.org/10.1016/j. wasman.2018.03.001

16. Sakai S (2000) Material cycles science concept. Environ Sci Pollut Res Int 7(4):225-232. https://doi.org/10.1007/BF02987353

17. Paul H Brunner, (2010) Clean cycles and safe final sinks. Waste Manag Res 28(7):575-576

18. Brunner PH, Rechberger H (2016) Handbook of material flow analysis: for environmental, resource, and waste engineers. CRC Press, Boca Raton

19. Kral U, Vyzinkarova D, Brunner PH (2015) Schutz und Nutzung von Senken durch die Zürcher Abfall- und Ressourcenwirtschaft [Endbericht] (in German). Technische Universität Wien. Wien. URN: urn:nbn:at:at-ubtuw:3-3689, PURL: http://resolver.obvsg. at/urn:nbn:at:at-ubtuw:3-3689. Accessed 8 June 2018

20. BAG (2012) Factsheet: Polyzyklische aromatische Kohlenwasserstoffe (PAK) (in German). Bundesamt für Gesundheit (BAG). Bern

21. Kim KH, Jahan SA, Kabir E, Brown RJ (2013) A review of airborne polycyclic aromatic hydrocarbons (PAHs) and their human health effects. Environ Int 60:71-80. https://doi.org/10.1016/j. envint.2013.07.019

22. Umweltbundesamt (2016) Polyzyklische aromatische kohlenwasserstoffe. Umweltschädlich! Giftig! Unvermweidbar? (in German). Hintergrund. Dessau-Roßlau. Retrieved from https://www. umweltbundesamt.de. Accessed 16 Nov 2017

23. Statistisches Amt des Kantons Zürich (2017) Kanton Zürich in Zahlen 2017 (in German). Zürich. Retrieved from https://statistik. zh.ch. Accessed 3 July 2018

24. Wittmer D (2006) Kupfer im regionalen Ressourcenhaushalt - Ein methodischer Beitrag zur Exploration urbaner Lagerstätten (in German). PhD Thesis, ETH Zürich, vdf, Hochsch.-Verl. an der ETH. ISBN 13: 978-3-7281-3047-1, ISBN 10: 3-7281-3047-8

25. Huisman J, Leroy P, Tertre F, Söderman M, Chancerel P, Cassard D et al (2017) Prospecting secondary raw materials in the urban mine and mining wastes (ProSUM) - final report. Brussels, Belgium. Retrieved from http://www.prosumproject.eu/. Accessed 16 Feb 2018, ISBN: 978-92-808-9060-0 (print), 978-92-808-9061-7 (electronic)

26. EU (2008) Directive 2008/98/EC of the European Parliament and of the Council of 19 November 2008 on waste and repealing certain Directives. Retrieved from https://eur-lex.europa.eu. Accessed 15 June 2017

27. European Commission (2015) Proposal for a Directive of the European Parliament and of the Council amending Directive 2008/98/EC on waste. Brussels. Retrieved from https://eur-lex. europa.eu. Accessed 8 Feb 2018

28. Rechberger H, Laner D (2017) Striving for efficiency: Optimum vs. maximum recycling targets. CEC4Europe publication project. Vienna. http://www.cec4europe.eu. Accessed 10 Apr 2018 